\title{
SAFETy Management OF COMPleX FACILITIES
}

\author{
Dana Prochazkova, Jan Prochazka, Miroslav Rusko, \\ Vojtech Kollar, Milan Majernik, Jan Ilko \& Stefan Majernik
}
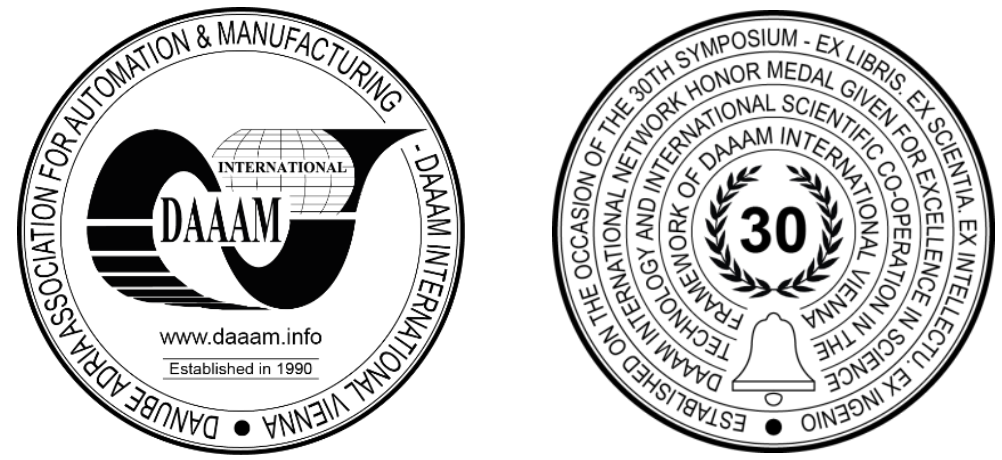

This Publication has to be referred as: Prochazkova, D[ana]; Prochazka, J[an]; Rusko, M[iroslav]; Kollar, V[ojtech]; Majernik, M[ilan] \& Ilko, J[an] (2020). Safety Management of Complex Facilities, Proceedings of the 31st DAAAM International Symposium, pp.0366-0375, B. Katalinic (Ed.), Published by DAAAM International, ISBN 978-3-902734-29-7, ISSN 1726-9679, Vienna, Austria

DOI: $10.2507 / 31$ st.daaam.proceedings.051

\begin{abstract}
The safe community is now at time of globalisation very dependent on a safety level of complex facilities ensuring the territory by basic service necessary for human live, e.g. the electric energy on which there are dependent supplies of good quality drinking water, utility water, information distribution etc. Series of events from recent years connected with complex facilities failures showed their high importance. The complex facility represents multistage mutually overlapping systems, the type of which is a system of systems. The paper presents the model for complex facilities safety management based on the combination of principles: All-Hazard-Approach and Defence-In-Depth. It shows the way how to manage the safety of individual complex facility systems and the whole complex facility in time.
\end{abstract}

Keywords: Complex facility; Provision of territory services; Security; Safety; Model for complex facility safety management.

\section{Introduction}

For ensuring the human security and development, the safe human system is necessary [1], [2], [3]. Ensuring the safe human system is not easy, because the human system is a system of systems [21], i.e. system of several mutually interconnected systems of a different nature. Consequences of interconnections (interfaces) are mutual dependences, the character of which is physical, cyber, territorial and organisational [20]. Mentioned interdependences are the sources of further vulnerabilities of human system that magnify the integral risk of a given system by increase of cross-section risks in the system of systems [4]. As a consequence of growing globalisation the new sources of disasters take on force, they also cause complex facility failures [17], [23]. The paper deals with problems of complex facility in the broadest concept, i.e. not only from the point of view of complex facility itself, i.e. from the viewpoint of its structure and co-operation of its individual parts, but also from the viewpoint of its impacts and profits for a given locality in that it is in operation, i.e. for public assets in locality and region [18]. The paper concept includes the public protection, i.e. humans need complex facilities because they: are sources of energy; ensure drinking water quality or products needed for daily needs; ensure supply of foods etc. But most of them need to operate them very carefully because their accidents can have long term consequences on public interest. From the reasons of fulfilment of targets of humans (human security and development) that may be only realised if human communities are in safe territory [19], [22], the object of present paper is the complex 
facility safety that ensures the safe complex facility that do not threaten neither themselves nor them vicinities, i.e. also another systems with which they are mutually interconnected or which they influence. The result of study, by help of methodology processed in the frame of project FOCUS [4] and the combination of principles: All-Hazard-Approach and Defence-In-Depth, is the creation of model of complex facility safety management in time.

\section{Complex facility}

The complex facility includes the facilities that are parts of different technological systems that ensure the human society needs [4]. Each of considered systems consists of the control system and controlled systems [4], which are for company processes, social system (humans, organisational structures, assets and values, knowledge), and for own technological system (tools, equipment, procedures, technologies). It means that they are multistage systems at which among the individual stages in both directions they run flows of materials, finances, information and decisions.

From mentioned reasons the systems needs are necessary to be also analysed from the viewpoint of interactions and interdependences among the technical, human, social and organisational aspects of a system. The exception is the analysis of human survival that is either active or passive. The capability of passive survival is included in the system properties, there are based on knowledge on defects in environs; the defects are illustrated by causal chain. The capability of active survival manifests by system behaviour, it considers uncertainty in projection of future defects and failures. From the methodological viewpoint the complex facility and each its partial part is a system of systems [4]. In engineering disciplines directed to risk at present we use two disciplines for trade-off with the risk [4]: a set of disciplines the target of which is the complex facility security, i.e. security of complex facility without regard to complex facility vicinity (security management); and a set of disciplines the target of which is the complex facility safety, i.e. security and development of both, the complex facility and its vicinity.

Many professional works deal with ensuring the first target, which has been pursued in engineering disciplines since the beginning of 80s [4]; see the reliability engineering the main part of which it was security. The other discipline target is more ambitious on understanding, accessible data and methods of engineering disciplines. It has been pursued since a half of 80s but from reasons of big demands on: data (there are necessary data on: system, system vicinity, linkages and flows between system and its vicinity); comprehension of problems and their connections in a case of open system of systems; methods of problem structuring, analysis and solving the problems, it is only enforced in domain of very advanced technologies as nuclear ones and astronautics [4], namely in spite of it solves interconnection of targets of humans in domains social, environmental and technological [3]. According to the IAEA requirements [5] the nuclear facility safety management is realised in practice but the critical analysis of nuclear accidents [6] show that also here it is necessary to upgrade the management of safety; e.g. it is necessary to upgrade the prevention of organising accidents, to improve maintenance of very critical parts etc.

\section{Relevant terms, facilities under account and safe complex facility}

Regarding to present way of problem solving given above, we use two concepts for ensuring the safe entity [4]; i.e. security management and safety management. The first mentioned concept being simpler is more often used in practice; i.e. the target is the complex facility security and impacts of complex facility on its vicinity are out of interest. The other ensures both, the complex facility security and the security of vicinity of complex facility. With regards to works [3], [4] the definitions of terms connected with security and safety are:

- Each complex facility alone is a multistage system in which among individual stages in both directions they run material, finance, information and decision flows.

- The disasters for parts of complex facilities and the whole complex facility are the phenomena that caused damages and losses. They include phenomena belonging to the category „All-Hazards-Approach” [7] and specific phenomena connected with humans and their behaviour that do harm the both, the complex facility owners and operators prosperity and the fulfilment of tasks for which they were established (insufficient co-ordination of activities organising accidents, failure of outsourcing activities, intent attacks etc.).

- The complex facility vulnerability is a predisposition of complex facility (its protected assets) to harm / damage origination.

- The complex facility resilience is a complex facility capability to overcome impacts of a given disaster. To reach sufficient resilience, it is necessary to apply together above mentioned „All-Hazards-Approach” and "Defence-InDepth" principle [4].

- The complex facility risk is a probable size of losses, harms and detriment caused by a disaster with size of normative hazard (mostly design disaster) on complex facility and public assets or subsystems rescheduled on selected time unit (e.g.1 year), site unit (e.g. $1 \mathrm{~km}^{2}$ ) and on basic assets of owners and operators of complex facility.

- The complex facility security is a situation / condition at which the probability of complex facility assets' harms, damages and losses is acceptable (it is almost sure that harms, damages and losses cannot origin).

- The complex facility safety is a set of measures and activities for ensuring the security and sustainable development of complex facility, its assets and public assets (i.e. also that are in the surrounding). 
- The complex facility security management is a planning, organisation, allocation of resources, humans and tasks with aim to reach demanded safe level of a complex facility alone (secured complex facility).

- The complex facility safety management is a planning, organisation, allocation of resources, humans and tasks with aim to reach demanded safe level of complex facility and its vicinity.

- The complex facility safety engineering is a set of engineering measures and activities by which the complex facility safety is ensured in real conditions of a given site.

With regard to results from analyses of complex facility safety and historical experiences, performed on the data given in the professional literature [1], [4] and in sources quoted in given works and in database [6], it is necessary to follow all complex facilities that ensure the energy production and distribution, water supply, sewer handling, transport system, communication and information systems, bank and finance system, emergency services (police, fire rescue service, medical rescue service), basic services (food supply, waste liquidation, social services, funereal services), industry, agriculture, state and regional administrations, that are usually supported by the national legislative. To them there is necessary to join the complex facilities for both, the education and the research, which is supported by the EU legislation. The safety and risk are not complementary quantities (the first one depends on level of human making and the other depends on level of site danger even though they together relate by a certain way. In each system both quantities depend on processes, acts and phenomena being under way in a given system and in its vicinity. In advanced concept the concentration to safety has higher targets than concentration to risk because it follows the system security, system development, system existence, system vicinity existence and co-existence of different systems [4]. It is the consequence of fact that the safety management is based on both, the high qualified trade-off with risk and moreover on the human capability to penetrate into the problem of risk manifestation and in advance to prepare mitigating steps. The risk sources are all phenomena included in the term ,All-Hazards“[7], the phenomena specified in work [8] and further fulfilled during the FOCUS project (from 77 disasters followed now in 2035 the number of disasters increases to 105) [9]. The risks connected with complex facilities are:

- partial ones that include risks connected with individual protected assets,

- integrated ones that include risks connected with several assets aggregated by a defined way,

- integral ones that include risks connected with all protected assets, with linkages and flows among assets that cause couplings among assets, partial systems and with vicinity.

It is clear that to be able to ensure the system safety, the system integral risk needs to be considered, managed and tradedoff.

\section{Method of complex facility safety management model building}

With regard to the present knowledge it is necessary to give that for complex facility safety management fundament, it is the risk analysis, risk assessment and trade-off with risks connected with mutual interconnections in complex facility sectors and in whole complex facility (i.e. in agreement with [4], [8] it is necessary to consider interdependences in a system of systems; i.e. at risk identification it is necessary also to use cross-sectional criterions). The procedure of work with risk is shown in Fig. 1. It starts with definition of concept of work with risk (system characteristics, determination of assets, specification of aims), on the basis of which risks are identified, analysed, assessed, judged, managed, tradedoff and monitored. Feedbacks denoted in this Figure 1 are used if risk level is not on required level [4] (because the costs on feedback application increase with increasing feedback order, the fourth feedback is only realised if safety concept fully fails, i.e. when basic risks were omitted).

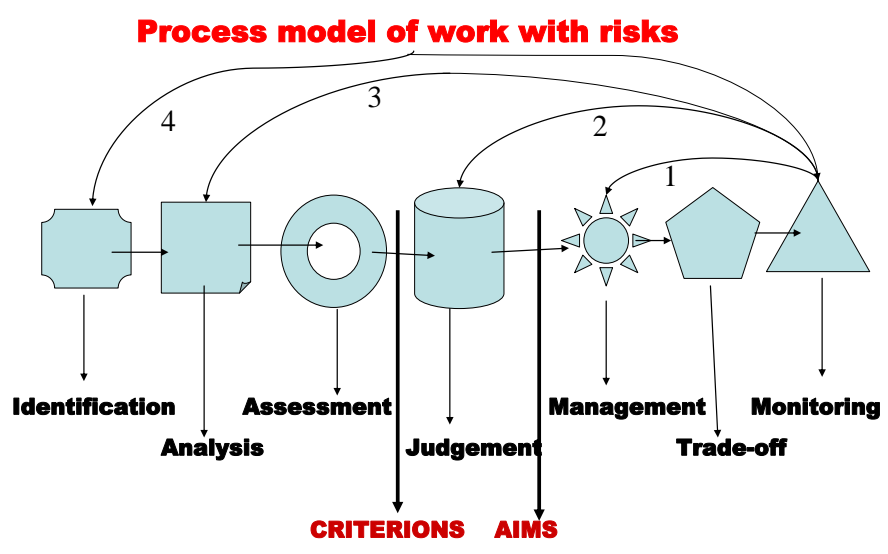

FEEDBACKS - 1, 2, 3, 4

Fig. 1. Process model of work with risks, numbers 1, 2, 3 and 4 denote feedbacks 
In present practice we distinguish five different concepts for work with system risks, Fig. 2, which are summarized and described in work [4]. For human safety and for human system safety (i.e. territory, organisation, plant) we need to manage the integral risk including the human factor, i.e. to find the way of cross-section risks management and to concentrate the investigation on interdependences and critical spots with a potential to start the system cascade failures, domino effects, strange behaviour etc., and on the basis of such site knowledge to prepare measures and activities ensuring the continuity of limited nuclear facility operation and of the human survival.

The assessment of criticality of individual systems (sectors) of complex facility and the whole complex facility is not trivial matter because under different conditions the sectors and the whole have a different role - active, reactive, critical or damping (not additive); e.g. the existence of several variants of electricity supply to one site decreases the energy complex facility criticality but it increases expenses etc.

The purpose of model for complex facility safety management is to show basic steps by which it is possible to ensure the complex facility security and complex facility vicinity security. The model building method goes out from a system concept of complex facilities; it considers them as system of systems (several overlapping systems) [4], [8], which means that their complex behaviour, function and development depend on both, the number and properties of partial systems and the diversities of their interconnections, i.e. their linkages and flows among them and also across them. The linkages and flows going across the partial systems are the originators of internal dependences (interdependences). The presented model is created by method of analogy to existing safety management models [3], [4], [8].

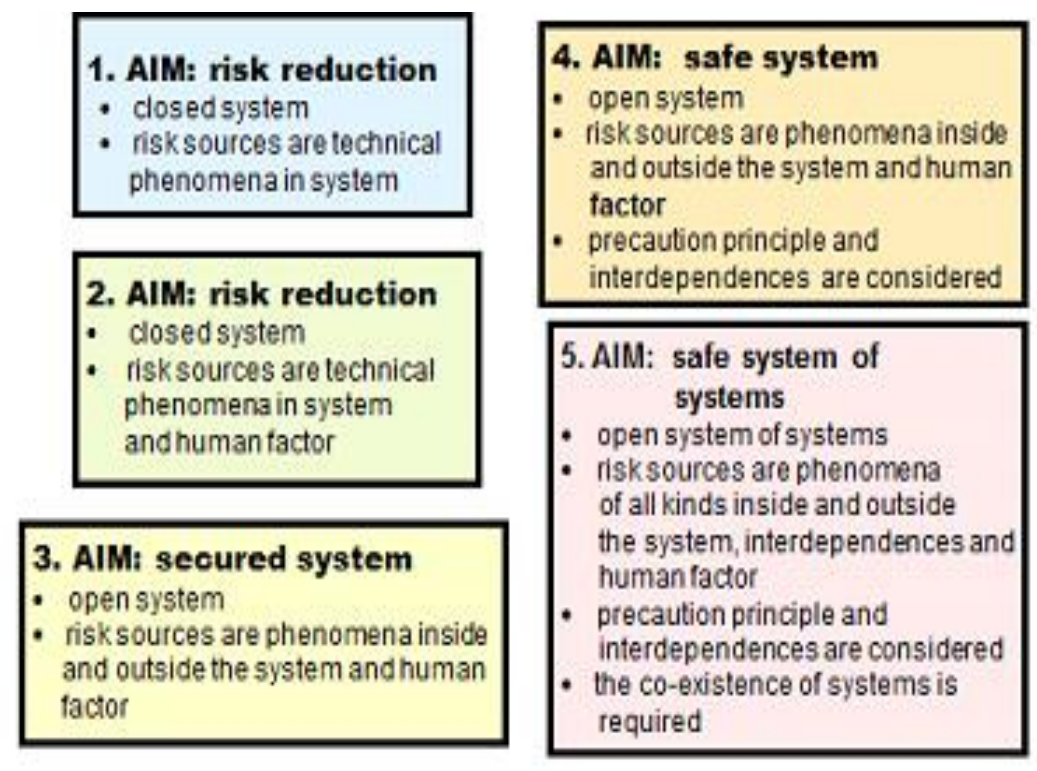

Fig. 2. Concepts of risk management and engineering trade-off with risks and their objectives, arranged in chronological order according to the introduction to engineering practice

At complex facility safety management we need to concentrate to critical items, and therefore, it is necessary to judge the criticality of both, the individual items and the whole. The method for judgement of criticality of individual facilities and of whole set of complex facilities is described in [10].

\section{Model for complex facility safety management in time}

With regard to: data and knowledge in [3], [4], [8], [9], [10], [11], [12], [13], [14], [15]; the concept promoted by the OECD [16]; the method described in works [4], [8]; and the assumption that each complex facility is an open system (i.e. risk sources are internal and external disasters and human factor [3], [4] and [8]), it is created a model for safety management having six processes, i.e.: concepts and management; administrative procedures; technical matters; external cooperation; emergency preparedness; and the documentation and the investigation of accidents (Fig. 3).

The processes are further divided into sub processes:

- The first process consists of sub processes for: the overall concept; achieving the intermediate objectives of safety; leadership / management of safety; the safety management system; personnel staff including the sections for: human resources management, training and education, internal communication / awareness and working environment; review and evaluation of the implementation of the fulfilment of objectives in the safety.

- The second process consists of sub processes for: identify of hazards from potential disasters and risk assessment; documentation of procedures (including work permits); management of change; safety in conjunction with contractors; and supervision of product safety. 
- The third process includes the sub processes for: research and development; design and mountings; inherently safer processes; technical standards; storage of hazardous substances; and maintenance of integrity and maintenance of equipment and buildings.

- The fourth process includes the sub processes for: cooperation with the administrative authorities; cooperation with the public and other stakeholders (including the academic institutions); and cooperation with other facilities.

- The fifth process includes the sub processes for: planning of internal (on-site) preparedness; facilitate the planning of external (off-site) preparedness (for which it corresponds the public administration); and the coordination of the activities of the departmental (resort) facilities at ensuring the departmental emergency preparedness and at response.

- The sixth process has sub processes for: processing of reports on disasters, accidents, near misses and other learned experience; investigation of damages, losses and harms and their causes; and the response and follow-up activities after disasters (including lessons learned and information sharing).

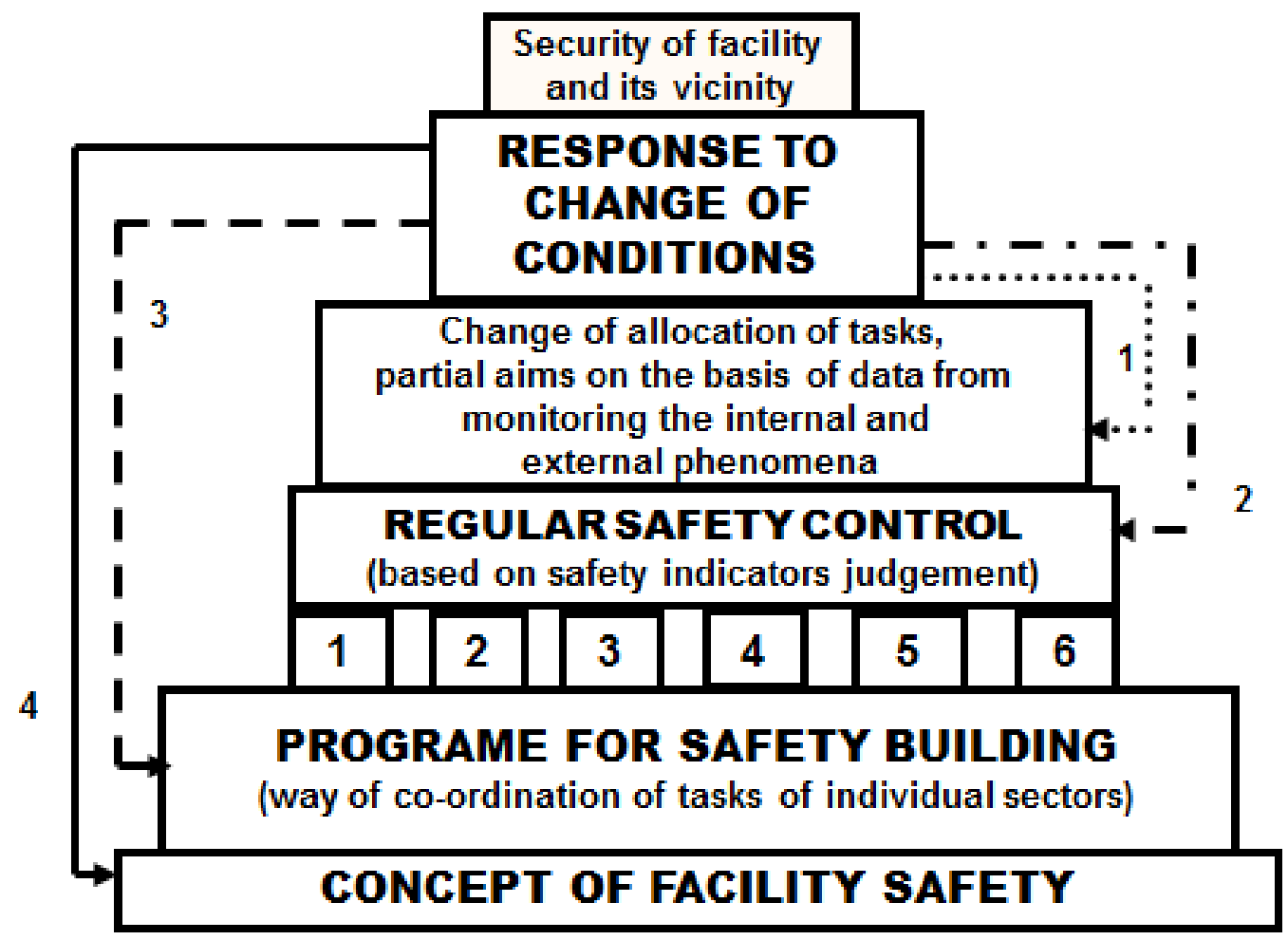

Fig. 3. Model of management of complex facility safety; bottom block - concept for specification of important processes of nuclear facility; dotted line - feedback 1; broken line - feedback 2; dashed line - feedback 3; full line feedback 4

Coordination of processes is targeted at ensuring the safe facilities under the conditions of normal, abnormal and critical (Fig. 4). From Fig. 3 it follows that for each concept of complex facility safety it is necessary in the first to compile the programme for complex facility safety formation in which we establish the way how the individual sectors that manage main processes will co-ordinate their works so tasks of complex facility were efficient, economical and timeous, and the timetable.

Because each facility is in dynamic development the states of tasks performance need to be regularly judged by help of safety indicators (for trend and rate of target achievement) using the monitoring data. In case of abnormal deviations from targets of timetable, the corrections need to be done (e.g. allocation of tasks, partial aims, relocation of sources etc.). In the case of critical conditions (too big deviations from targets of timetable), the response to critical conditions needs to be performed. According to relevance of change of conditions the appurtenant feedback is selected; in Fig. 3 you can see that the application of feedback 4 means the change of facility safety concept. Because the costs on feedback application increase with increasing feedback order, the fourth feedback is only realised if safety concept fully fails, i.e. when the nuclear facility failure assessment shows that priority basic risks were omitted in original concept.

The safety management system (SMS) of facility operators includes the organisation structure, responsibilities, practices, rules, procedures and sources for determination and invoking the prevention for disasters that are results of processes inside and outside of facility or at least mitigation of their unacceptable impacts. As a rule it is connected with many aspects, apart from the organisation of employees, identification and assessment of hazard size, risk size, organising system, management of changes, emergency and crisis planning, safety monitoring, audits and scrutiny processes. 


\section{CONCEPT OF FACILITY SAFETY}

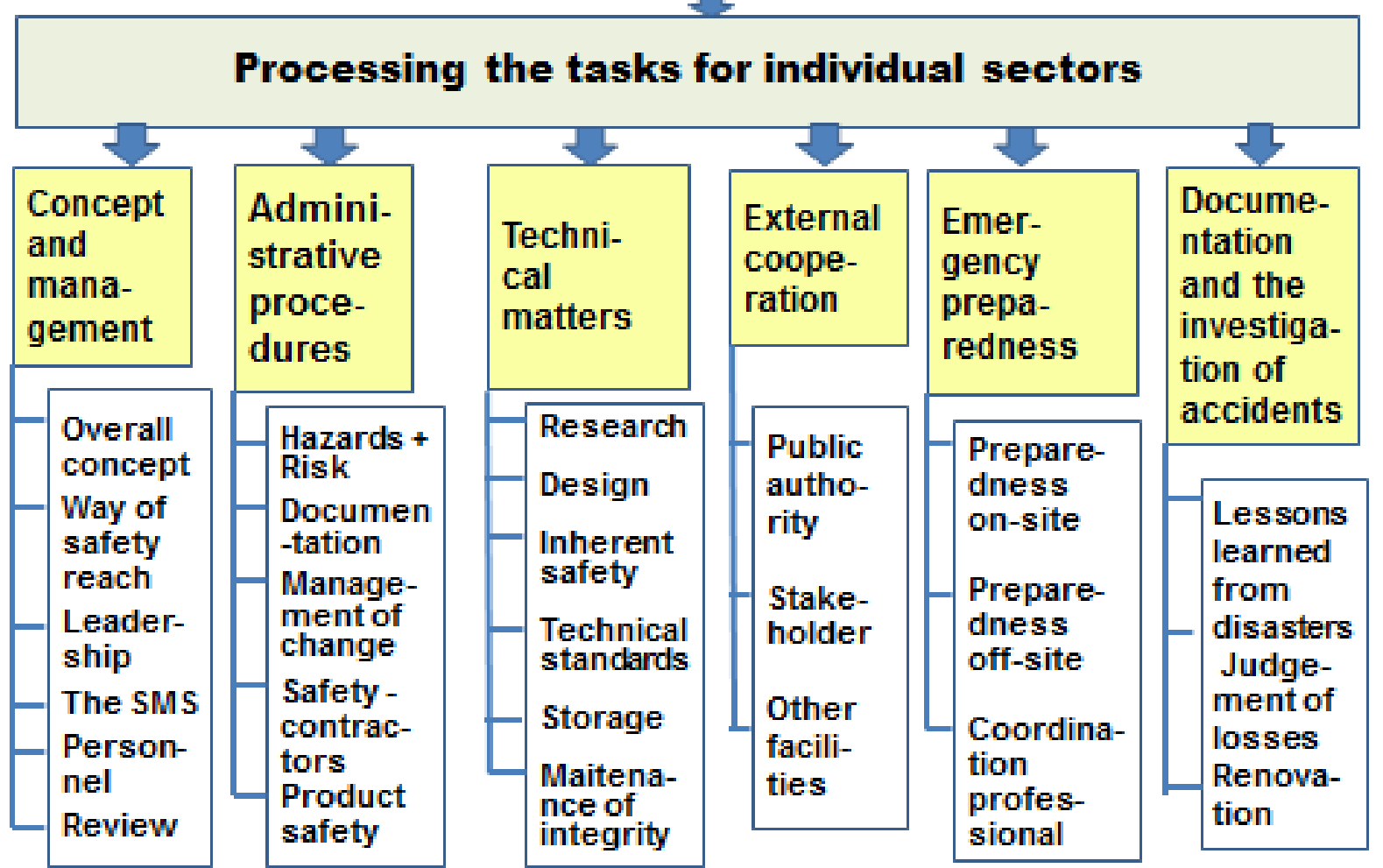

Fig. 4. Concept of facility safety and its main parts

With regard to data in works [3], [16] the program for increase of complex facility safety has the following steps:

- Determination of tasks (partial targets) and strategic goals for facility with regard to safety directed to security of both, the facility and the facility vicinity.

- For each process that is connected with facility to determine suitable target and running indicators for safety level judgement.

- To process dictionary for needs connected with integral safety management.

- To harmonize standards, good practice methods and local procedures.

- To determine set of target indicators.

- To determine set of running indicators.

- To determine way of assessment of target indicators specific for a given supply chain.

- To determine way of assessment of running indicators specific for a given facility.

- To determine way of assessment of all indicators together and marginal limits for a given facility.

In practice it means that for each sector of selected authority the target and running indicators are determined and they have form of limits and checklists [3], [16]. To them there are assigned criteria for assessment and scales by which it is determined if target is reached or is not reached. For creation of an effective safety management system the basic principle is that all participants play certain roles and at safety realization they need to fulfil these roles.

Because the world dynamically changes it is necessary to follow continuously the safety level, i.e. the size of integral risk that includes also the cross-sectional risks connected with interdependences and important partial risks of complex facility. In case that limits and conditions are not kept, it is necessary to perform changes as shown feedbacks in Figure 3. Because changes requires sources, forces and needs, firstly it is realised feedback 1 and only if it does not ensure expected result the feedback 2 is realised etc. Only in the case of occurrence of extreme phenomena with catastrophic impacts, the feedback 4 is immediately realised.

Safety management system for complex facility is lean on the concept of disaster prevention or at least of mitigation of severe disaster impacts that include the obligation to introduce and keep the safety management system [3], [16] in which the following problems are taking into account: 
- roles and responsibilities of persons participating in important hazards management on all organising levels and in ensuring the training,

- plans for systematic identification of important hazards and risks connected with them that are connected with normal, abnormal and critical conditions, and for assessment of their occurrence probability and severity,

- plans and procedures for ensuring the safety of all components and functions, namely including the object and facilities maintenance,

- plans for implementation of changes in territory, objects and facilities,

- plans for identification of foreseeable emergency situations by a systematic analysis including the preparation, tests and judgement of emergency plans for response to such emergency situations,

- plans for continuous evaluation of harmony with targets given in safety concept and in the SMS, and mechanisms for examination and performance of corrective activities in case of failure with aim to reach determined targets,

- plans for periodic systematic assessment of safety concept, effectiveness and convenience of the SMS and of criterions for judgement of safety level by top workers group.

It is necessary to ensure:

- The qualified risk management of disasters, the sources of which are inside and outside of complex facility plus human factor; i.e. it follows complex facility and parameters of vicinity in which complex facility operates. It is composed of: assessment of expected disaster size; determination of occurrence probability of important disasters; judgement of complex facility vulnerabilities at important disasters; determination of impacts of important disasters on complex facility. It creates a base for ensuring the safe complex facility.

- The designing and planning the measures and activities for ensuring the facility security at considering all important disasters [3], [7]; i.e.: facility layout (structure, function, sitting, buildings, equipment); performing the measures and activities for ensuring the facility security; plan of renovation of facility after disaster; plan of training the personnel performing the facility; facility activities' monitoring; and correcting measures and activities for a case of important deviations in facility operation.

- The designing and planning the measures and activities for ensuring the complex facility vicinity security at considering all important disasters [3], [7]; i.e.: facility layout by a way that it may not threaten vicinity, i.e. all public assets; performing the measures and activities for ensuring the facility vicinity security; plan of renovation of facility vicinity after disaster; plan of training the personnel performing the facility; facility activities' monitoring; and correcting measures and activities for a case of important deviations in facility operation.

- The harmony among the main activities connected with facility commodities, i.e.: subject of supply (its manufacture, transport and distribution); following the deviations in a process of commodity management; and operating loops. It goes on ensuring the stabilities of processes, the minimisation of delays, the quality and the other critical aspects connected with the operation.

- The safe assets of facility, i.e. problems connected with: facilities, equipment or services; vehicles; shipping; products; and data systems. It also goes on averting of insiders activities.

- The safe human sources, i.e. problems connected with: acceptation of employee; understanding the employee behaviour features important for facility operation; employee training; employee self-control; implementation of procedures that ensure correct employee behaviour; and employee stimulation.

- The good business partners, i.e. problems connected with: screening the possible partners; authentication of possible partners; producing the ways of negotiation with partners regarding to their behaviour; monitoring the partners behaviours; and audits of partners.

- The capabilities for overcoming the impacts of extreme disasters that affect complex facility, i.e. problems connected with: business continuity; specific response training; investigation of causes of extreme impacts; assembling the evidences; reparation of harms; and court settlement.

- The dislocation of criminal and illegal facilities and chains, i.e. problems connected with: formation of base for disruption (ensuring the sources, determination of means, logistics, transport of means, distribution of means); and with support of governments and customers.

- The integral safety of complex facility, i.e. the coordination of all pillars, i.e. processes directing to complex facility safety (PSM - process safety management).

Fig. 5 shows the process safety management for complex facility. Fig. 6 shows the domains that need to be kept in harmony for achievement of complex facility safety. Figure 7 shows the structure of plan ensuring the safe complex facility. 


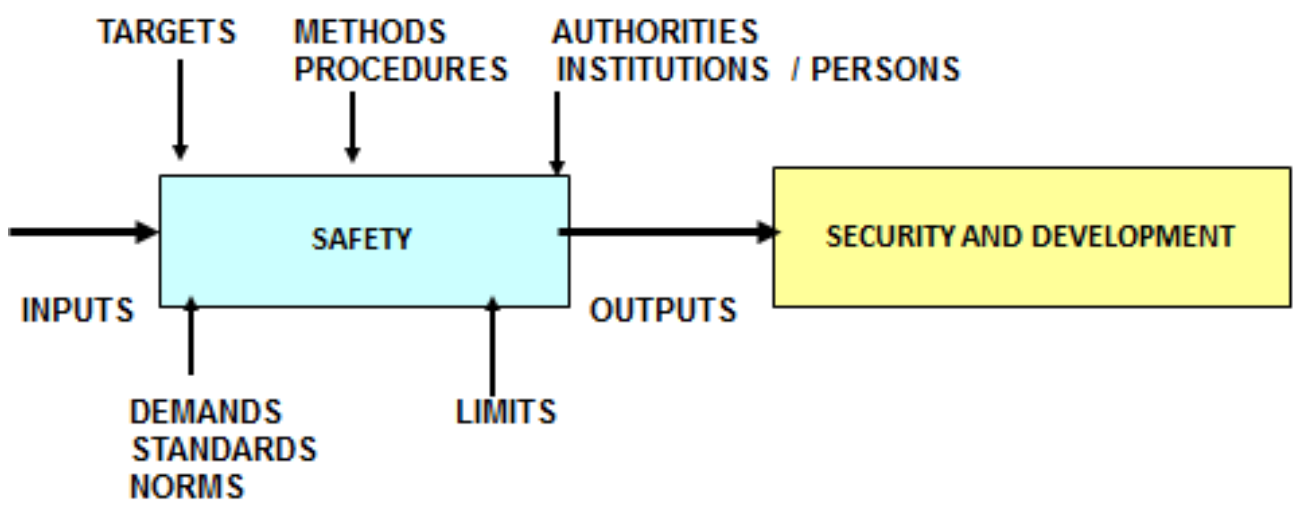

Fig. 5. Process of complex facility safety management

6. Results of inspections directed to judgement of consistency of real facilities safety performance with demands of ideal model

The ideal model of safe nuclear facility was created by application of All-Hazard-Approach and Defence-In-Depth concept [4]. The comparisons of this model with real results of detailed inspections in 12 complex facilities, given in [6] show that:

- Top safety management is insufficient; it is not based on use of AII-Hazard-Approach (only some disasters are considered) and integral risk at sitting, designing, building and operating the structures, components, equipment and systems.

- Interdisciplinary communication with connection over different safety management levels is missing.

- Safety requirements are not solved in all domains; and therefore, some serious risks can be neglected.

- Human faults are not often sufficiently considered; especially at decision-making on expensive protection measures and equipment that is necessary for human safety.

- The interdependences are not especially considered as the cause of failure of critical facilities.

- Defence-In-Depth concept is missing for crucial objects in network.

- Safety and security aspects are solved separately; mutual relations are not continually analysed.

- Current legislative respects security only in some domains of railway system.

- Relations and flows over boundaries of system under consideration are not solved.

\section{What to improve?}

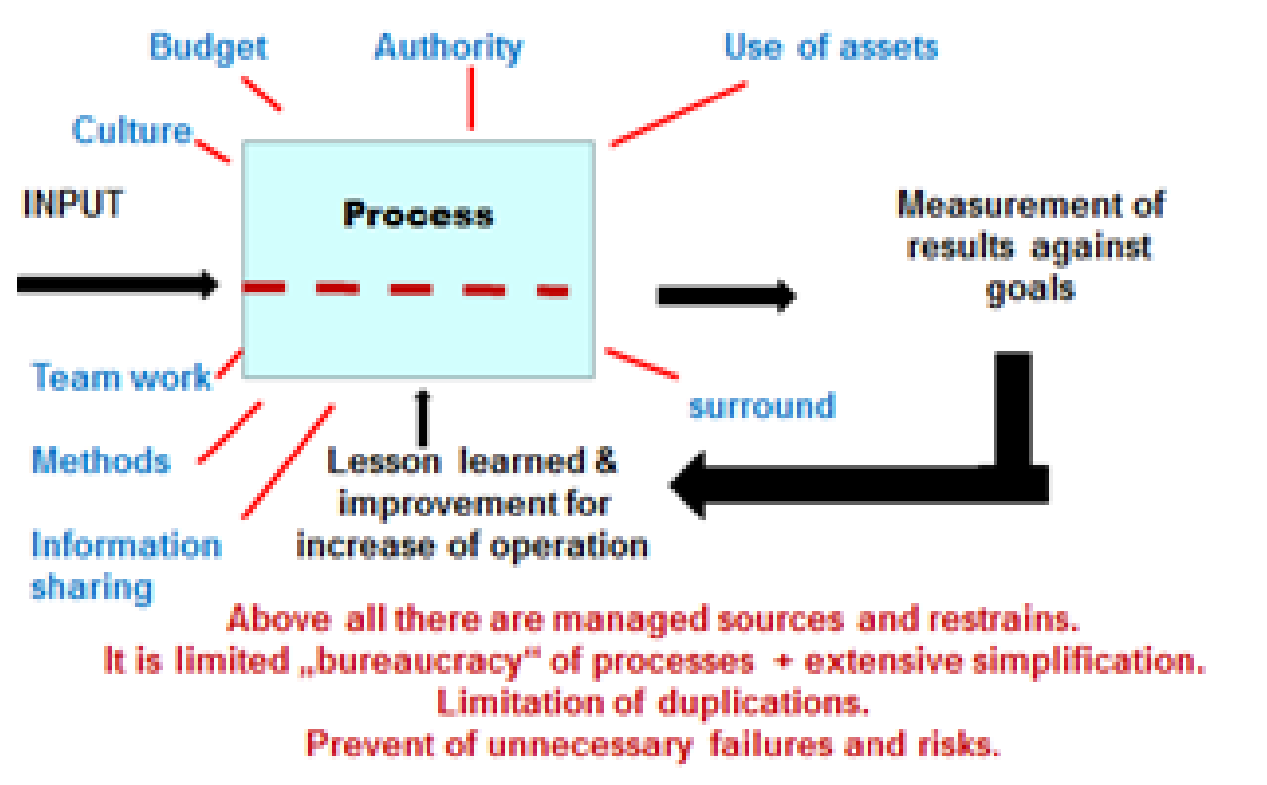

Fig. 6. The domains important for facility long-term safety achievement 


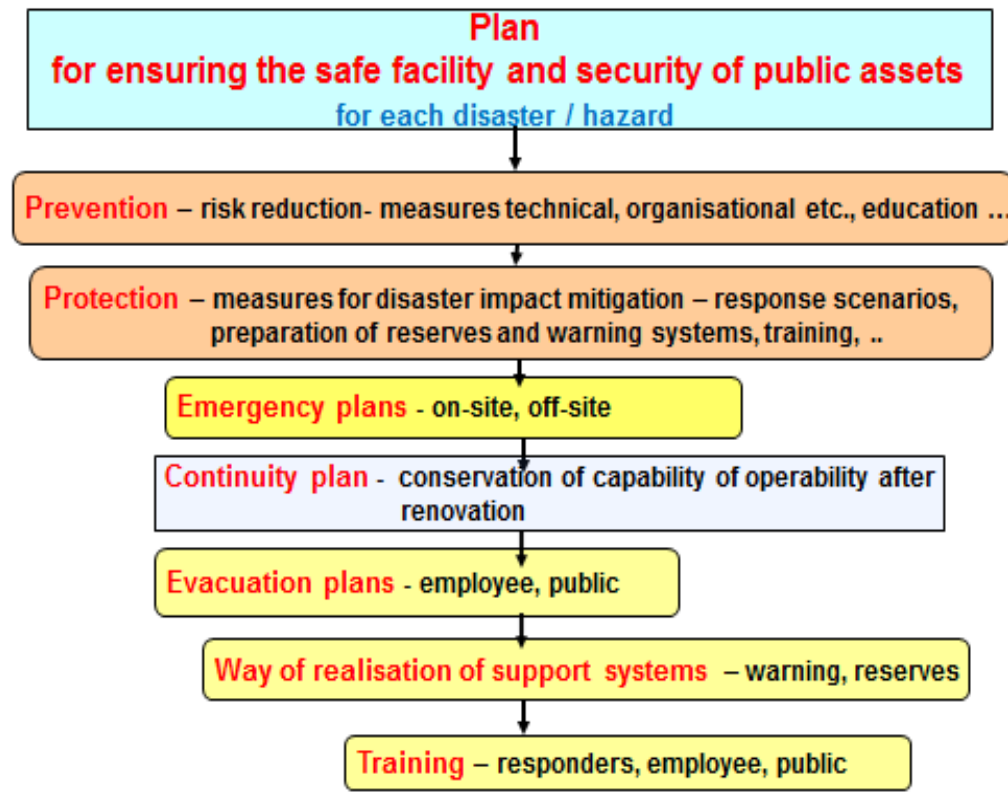

Fig. 7. Structure of plan ensuring the safe facility

\section{Future research plans}

The further research is planned to focus in particular on the aplication of suggested model for safety management of complex facilities compiled on the basis of present knowledge in context of process of safety management, based on qualified work with integral risk and the feedbacks.

\section{Conclusion}

Model for safety management of complex facilities compiled on the basis of present knowledge is the process model in which they are represented the both:

- the individual important elements of process of safety management based on qualified work with integral risk,

- the feedbacks by which it is possible to correct cases in which demands of safety are not fulfilled owing to dynamical development of complex facility and its vicinity.

For application in practice the model for complex facility safety management is supplemented by mechanism for ensuring the capability to be effective at abnormal and critical conditions. To ensure the complex facility safety during its life cycle including the human survival it is necessary to use: the mentioned concept of work with system risks which is directed to system of system`s safety; to interface „All-Hazards-Approach” and "Defence-In-Depth” principle; safety management programme based on model of management of complex facility safety shown in Fig. 3; process of facility safety management shown in Fig. 5; consideration of all domains shown in Fig. 6; and security plan the structure of which is in Fig. 7.

\section{Acknowledgement}

The results published in the article were created with the support of the project "RIRIZIBE" CZ.02.2.69 / 0.0 / 0.0 / 16-018 / 0002649 and project SSZP 4771675/2019.

\section{References}

[1] UN. Human development report. New York 1994, Available from: www.un.org

[2] EU. Safe Community. PASR projects, Brussels 2004.

[3] Procházková, D. (2011). Strategic management of territory and organisation (in Czech). ISBN: 978-80-01-04844. Praha. ČVUT, 483p.

[4] Procházková, D. (2015). Safety of complex technological facilities. ISBN: 978-3-659-74632-1. Lambert Academic Publishing, Saarbruecken, 244p.

[5] IAEA. (2011). Action Plan on Nuclear Safety. Vienna: IAEA. Available from: www.iaea.org

[6] CVUT. Czech Technical University in Prague, faculty of transportation sciences archives. 
[7] FEMA. (1996). Guide for all-hazard emergency operations planning. State and Local Guide (SLG) 101. Washinton: FEMA.

[8] Procházková, D. (2011). Analysis and management of risks (in Czech). ISBN: 978-80-01-04841-2. Praha: ČVUT, 405p.

[9] EU. FOCUS project. Brussels: EU. Available from: www.focusproject.eu

[10] Procházková, D. (2013). Criticality of transport nuclear facility (in Czech). Periodica Academica, ISSN: 1802-2626, VIII-2013, No. 2, pp 112-128.

[11] Stein, W.; Hammerli, B.; Pohl, H. \& Posch, R. (Ed.) (2003). Critical nuclear facility protection - status and perspectives. Workshop on CIP, Frankfurt am Main. Available from: www.informatik2003.de

[12] Moteff, J.; Copeland, C. \& Fischer, J. (2003). Critical nuclear facilitys: What makes an infrastrucuture critical? Report for Congress, CRS Web, Order Code RL31556.

[13] CISP. (2005). Workshop on critical nuclear facility protection and civil emergency planning-dependable structures, cybersecurity, commnon standard. Zurich: Centre for International Security Policy 2005, Available from: www.eda.admin.ch

[14] Rinaldi, S. M. (2004). Modelling and simulating critical nuclear facilitys and their interdependencies. In: Proceedings of the 37th Hawaii International Conference on System Sciences-2004. Sandia: Sandia National Laboratories. Available from: http://ieeexplore.ieee.org/xpl/ freeabs_all.jsp?arnumber $=1265180$

[15] Rinaldi, S.M.; Peerenboom, J.P. \& Kelly, T.K. (2001). Critical nuclear facility interdependencies (identifying, understanding, and analysing). IEEE Control Systems Magazine, Vol. 21, December 2001, pp.12-25. Available from: www.ce.cmu.edu/ hsm/im2004/readings/CII-Rinaldi.pdf

[16] OECD. (2002). Guidance on safety performance indicators. guidance for industry, public authorities and communities for developing SPI programmes related to chemical accident prevention, preparedness and response. Paris: OECD, 191p.

[17] Kralikova, R.; Sokolova, H.; Wessely, E. \& Polak, J. (2013). Approaches to assessment of hot environment. DAAAM International Scientific Book 2013. Chapter 14. Vienna. pp. 317-328. ISBN: 978-3-901509-94-0

[18] Majernik, M.; Kupec, V.; Majernik, S. \& Zatrochova, M. (2011). Finančné riadenie podniku. Bratislava: STATIS, ISBN: 978-80-85659-67-2

[19] Procházková, D.; Wessely, E.; Rusko, M. \& Kralikova, R. (2011). Human System Safety Management and Environmental Management Relation. In DAAAM International Scientific Book 2011. pp. 103-118. ISSN: 17269687; DOI: 10.2507/daaam.scibook.2011.09

[20] Procházková, D. \& Rusko, M. (2017). Relation between human system safety management and environmental management. - In Journal of Environmental Protection, Safety, Education and Management. Vol. 5, No. 9, ISSN: $1339-5270$

[21] Prochazkova, D.; Prochazka, J.; Rusko, M.; Mikulova, M. \& Ilko, J. (2017). Model for critical infrastructure safety management. In Annals of DAAAM for 2017, Volume 28, No.1. The 28th DAAAM International Symposium. Zadar, Croatia, Vienna: DAAAM International, ISSN: 2304-1382. ISBN: 978-3-902734-14-3. DOI: 10.2507/28th.daaam.proceedings.085.

[22] Necesal, L.; Lukas, L. \& Jasek, R. (2011). Measures for critical infrastructure protection in the Czech republic. Annals of DAAAM for 2011 \& Proceedings of the 22nd International DAAAM Symposium, Volume 22, No. 1, ISSN: 1726-9679, Katalinic, B. [ed.] Published by DAAAM International, Vienna, pp. 0843-0844

[23] Lukas, L. \& Hromada, M. (2011). Risk analysis in context of kritical infrastructure protection. - Annals of DAAAM for 2011 \& Proceedings of the 22nd International DAAAM Symposium, Volume 22, No. 1, ISSN: 1726-9679, Katalinic, B. [ed.] Published by DAAAM International, Vienna 